Gretchen L. Hoffman-Texas Woman's University

\title{
Applying the User-Centered Paradigm to Cataloging Standards in Theory and Practice: Problems and Prospects
}

\begin{abstract}
Dervin and Nilan's (1986) article, "Information needs and uses," has been an influential article in Library and Information Science (LIS), because it calls for a paradigm shift in LIS away from research that focuses on systems and standards to research that focuses on users. This article also has been influential on library and information practice. Librarians and other information workers are called on to be user-centered and place users at the center of library programs and services. Conforming to the user-centered paradigm, however, has been problematic for broad representational systems, like library cataloging, that must meet the diverse needs of global users. Despite calls to focus on users, the cataloging field has not taken a user-centered approach in research or in the development of cataloging standards. Instead, the responsibility to meet users' needs has been placed on cataloging practitioners, who are encouraged to customize bibliographic records to meet their local users' needs. Dissertation research by Hoffman (2008) suggests that catalogers are limited in their ability to customize bibliographic records, because catalogers do not know who their users are and cannot identify their users' needs. In addition, library administrators discourage customization in favor of efficient cataloging processes. There are limits to LIS's user-centered paradigm in the area of cataloging, and perhaps it needs to examined and reconsidered. Is the user-centered paradigm still applicable to cataloging? How should cataloging meet users' needs? This paper will examine the problems of the user-centered paradigm in cataloging.
\end{abstract}

\section{Introduction}

Dervin and Nilan's (1986) review article, "Information needs and uses," has been influential in Library and Information Science (LIS) in shifting the focus of LIS research and practice from systems to users. Although there were earlier calls to focus on users (see e.g., Allen, 1969; Paisley, 1968), this article clearly called for a paradigm shift from research that focuses on systems, standards, and documents, to research that focuses on users and understanding users' information needs and searching behavior. Unlike the systems approach, which focuses on users in relation to systems, the userfocused, or user-centered, paradigm takes the user as the focus of research and seeks to "observe users in terms of users" (Dervin \& Nilan, 1986, 9). Users are viewed as individuals who actively construct information, and the research often takes a cognitive approach. This approach contends that if LIS understands what goes on in an individual user's mind (how a user conceptualizes his/her world), that knowledge can be used to better serve the user's needs (Ingwersen, 1996). This knowledge, then, can be used to design systems that account for a user's information needs and searching behavior (see e.g., Bates, 1989; Belkin, 1980). Dervin and Nilan's article also has influenced library and information practice. Librarians and other information workers are called on to be user-centered and should possess excellent customer service skills, understand and respect users' differences, and place users at the center of library programs and services (see e.g., Montanelli \& Stenstrom, 1999).

Conforming to the user-centered paradigm, however, has been problematic for broad representational systems and standards, especially those used in library cataloging, because they must meet the needs of a wide variety of users. Standards for 
descriptive cataloging, such as the Anglo-American Cataloguing Rules, controlled vocabularies, like the Library of Congress Subject Headings, and broad classification schemes, such as the Dewey Decimal Classification and the Library of Congress Classification, are increasingly being used by a global audience of users who represent many cultures and speak many different languages.

Despite calls for cataloging research to focus on users (see e.g., Borgman, 1996; Carlyle, 1999; Jeng, 1997) and cataloging standards to be built based on an understanding of users' needs (Hufford, 1991), the cataloging field has not really taken a user-centered approach in research or in the development of cataloging standards. Instead, the responsibility to meet users' needs has been placed on cataloging practitioners, who are encouraged to think about users and customize bibliographic records to meet the needs of their local users. However, meeting users' needs in practice has been challenging, because the job of catalogers is to apply standards, not necessarily to meet the needs of local users. There also are limits on the ability of catalogers to customize bibliographic records in practice, such as catalogers' lack of knowledge of local users and their needs, and library administrators who discourage customization in favor of fast production and efficient cataloging processes (Hoffman, 2008).

If cataloging standards are being used by more global and diverse users, is the usercentered paradigm still applicable? In addition, if catalogers in practice cannot customize bibliographic records to meet users' needs, who/what is responsible for meeting users' needs and how should those needs be met? In this paper, I will first discuss how cataloging currently focuses on users in research, standards, and practice. Then, I will discuss possible ways cataloging could focus on users. Although the focus in this paper is on library cataloging and cataloging standards, this discussion could be applicable to other areas of knowledge organization and other representational systems.

\section{How cataloging focuses on users}

Historically, North American cataloging practice has always tried to focus on users. For example, Cutter $(1904,6)$ instructs, "The convenience of the public is always to be set before the ease of the cataloger," and Haykin $(1951,7)$ asserts, "The reader is the focus in all cataloging principles and practice." This focus on users also can be seen in the recent Statement of International Cataloguing Principles (2009, 2), which states that the highest principle in the construction of cataloging codes is the "the convenience of the user" and that decisions should be made with "the user in mind." Yet, this directive only instructs catalogers to "think" of users during the cataloging process and the development of standards, not to try to meet their needs.

\subsection{Focusing on users in cataloging research and standards}

Although cataloging thinks about users, the focus is still on systems and standards, not understanding users' information needs and searching behavior, as advocated by the user-centered paradigm. This has implications for cataloging research and standards. When cataloging research deals with users, it generally does not take the user as its focus. Instead, research focuses on how users interact with or understand existing systems such as card/online catalogs, cataloging standards, or bibliographic records. Generally, the goal of this research is to make better matches between cataloging 
systems and users' queries (Bates, 1998; Dervin \& Nilan, 1986). Examples include the many catalog use studies that have been performed (for an overview see e.g., Borgman, 1986) and research that focuses on users' interaction with specific cataloging standards (see, e.g., Drabenstott et al., 1999). Rarely does research in this area take the user as the focus; one exception is Carlyle's (1999) research on user categorization of works. This is not to criticize this research or diminish its importance, but simply to point out that it is not the type of research called for by the user-centered paradigm.

Perhaps because cataloging research does not take a user-focus, cataloging standards have not been developed based on an understanding of users' needs, despite calls from researchers to do so (see, e.g., Carlyle, 1999; Hufford, 1991; Jeng, 1997). Standards are meant to be universal; they have not been developed to meet the needs of a wide variety of users, let alone the diverse needs of a global audience. Standards have been criticized, because they assume that users are a homogenized group that has similar needs, and they often fail to account for differences among users (Olson, 2004). Standards also have been criticized for their marginalizing effect and their bias toward male, white, Christian, American viewpoints (see, e.g., Berman, 1971, 1981; Olson, 2000, 2001, 2004). Although the Library of Congress has changed some of its subject headings and classifications to reflect less biased terminology, cataloging standards still focus on the universal user and have not been built based on an understanding of users' information needs.

\subsection{Focusing on users in cataloging practice}

If cataloging research and standards do not focus on users, then how does cataloging focus on users? How is cataloging a part of the user-centered paradigm? Instead of research and standards, the responsibility to meet users' needs has been placed on cataloging practice. Cataloging practitioners are called upon to leave behind their strict, rule-oriented, bureaucratic ways and to focus on users (see, e.g., McCombs, 1985; Stenstrom, 1999). The emphasis is placed on "local" cataloging, and catalogers are called on to customize bibliographic records to meet local users' needs (see, e.g., Olson, \& Schlegl, 2001; Weinberg, 1992). Customization is possible, because cataloging is shared among libraries through bibliographic utilities, like OCLC's Connexion database (WorldCat). On these utilities, there is supposed to be one universal, or master, bibliographic record per edition of a work. Catalogers are called upon to take that master record and modify it to meet the needs of local users. This sets up a two-tiered cataloging system in which there is one set of universal standards for the bibliographic utility, and another set of local standards for each individual cataloging department. The assumption is that catalogers can do anything they want on their own library catalog, but they must adhere strictly to standards in the bibliographic utilities.

On the surface, this seems like an effective way for the standards to remain universal, yet allow different types of users' needs to be met on the local level. However, this charge is problematic for cataloging practitioners. It assumes that catalogers can objectively determine their users' needs and will know how to adapt the standards to meet those needs. Dissertation research by Hoffman (2008) suggests that catalogers in academic libraries are hindered in their ability to meet users' needs, because they do not know who their users are and cannot articulate their local users' 
information needs. To catalogers in this study, standards represent users and catalogers believe that users' needs will be met by following standards. Finally, cataloging administrators are under constant pressure to increase production and improve efficiency. In order to reap the monetary benefits of shared cataloging, administrators in this study discourage the practice of customization and prefer to accept bibliographic records from the bibliographic utilities "as is" and/or purchase bibliographic records from vendors.

Yet despite these hindrances to customization, Hoffman (2008) suggests that catalogers at these libraries want to be a part of the user-centered paradigm and focus on users. Catalogers believe strongly that users are the ultimate purpose of cataloging. They try to "think" about users while cataloging, although they focus on standards in their behavior. However, instead of customization, catalogers and cataloging departments have had to redefine what it means to meet local users' needs. In this study, to meet the needs of local users, catalogers follow cataloging standards, perform rush processing, and are nice to faculty, staff, and students. Although the catalogers in this study are trying very hard to be user-centered and help local users, they cannot truly meet local users' needs through customization.

\section{How should cataloging focus on users?}

If cataloging practitioners are not able to customize bibliographic records to meet users' needs, how should cataloging focus on users? How can cataloging focus on users and be user centered in a global environment where standards are called on to meet the needs of many different users?

\subsection{Standards must focus on users}

The model for addressing users' needs seems to place users at the bottom of the hierarchy: Standards -> Catalogers -> Users. Catalogers are called upon to be a bridge between the standards and users and to modify the standards to meet local users' needs. However, if catalogers cannot customize bibliographic records in any significant way, this model needs to be changed so that users inform the work of standards. Users need to be placed at the top of the hierarchy: Users $->$ Standards $->$ Catalogers. Because the emphasis in practice is on following standards to ensure fast production and efficient work, there is more of a chance that users' needs will be met if standards focus on users and find ways to reflect their needs.

In addition to focusing on users in standards development, the assumption that cataloging can separate universal cataloging from local cataloging should be reexamined. 'Localized' interests, concerns, and values should be incorporated into the development of universal standards. There may still be a place for universality in standards, but they must meet the needs of various types of users. Cataloging practitioners may not be customizing bibliographic records to meet their local users' needs, and the responsibility to meet these needs cannot be placed solely on their shoulders. The universal needs to incorporate the local.

\subsection{Focus on domains}

How can universal standards really incorporate local needs? In the user-centered paradigm, research often takes a cognitive approach, which focuses on users as 
individuals. This is appropriate for some areas and research questions in LIS, but cataloging standards must reflect the needs of many different users. Focusing on domains may be a better approach to users and being user-centered. This approach is called the socio-cognitive approach, or the domain-analytic approach, and it focuses on users as parts of domains (Hjørland, 2002; Hjørland \& Albrechtsen, 1995). A domain involves "a group of people who share common goals" (Mai, 2004, 605), is predicated on a knowledge base common to members of that group, and requires socialization into the group in order to penetrate its standards of thought and practice. Like the cognitive approach, users are seen as active constructors of information. However, what happens in an individual user's mind is not as important as how context has shaped the user (Hjørland, 2002). It is important to understand how the members of a given domain produce and use information, how they search for information, and what questions they put to systems, because this knowledge can then be used to build systems of cataloging and indexing that help meet the specific needs of that domain (Hjørland, 2002; Mai, 2004).

Focusing on users as a part of domains could be a useful approach to users, because it would place the focus on groups of users, rather than any individual user, and it could provide a context for information use. This information could be incorporated into standards and bibliographic records to make information retrieval more meaningful in library catalogs. This is especially important as standards are called on to meet the diverse needs of a global audience. For example, Mai (2003) suggests that the needs of global users may be better served if the general and the special are both included in a classification scheme. A general classification scheme would not focus on describing what an item is about, but it could show the potential use by different domains.

A focus on use could be an effective way to bridge the universal and the local. This could not only be applied to standards for subject analysis, but for descriptive cataloging as well. As an example of this, I will look at the very broad domains of school libraries, public libraries, and academic libraries. Taking a domain focus, a bibliographic record for a children's book in a school library could look different from the bibliographic record for the same book in a public library or an academic library, because the users of the book may have different needs and use the book in different ways. For the school library, the bibliographic record may need to include curricular information for the teachers, as well as special programmatic information, such as Accelerated Reader levels (a popular program in schools to teach reading). The bibliographic record for the public library may need curricular information, particularly if the public library supports the school district. It also may need more summaries and series access so that children (and/or parents) can easily find a book they want to read. For an academic library, a bibliographic record for a children's book could include different types of information because the book is not intended to be read by children. It is used to train teachers and librarians. Although there could be universal attributes, like title, author, page numbers, etc., other things like notes, summaries, contents, etc. could show potential use. The bibliographic record could look different in all three libraries, because there are different needs and uses depending upon the domain. However, standards guide catalogers to create only one version of a bibliographic record. Without the ability to customize in practice, it becomes harder for libraries to meet the needs of local users. To overcome the limits of standardized cataloging, many 
libraries have to purchase specialized information from vendors. For example, many school libraries pay vendors to add curricular information to their bibliographic records

All of these different purposes can drive the development of standards. As cataloging standards are called on to meet diverse user needs on a global scale, there needs to be more research into incorporating domains into cataloging standards. There not only needs to be research on the domains themselves, but research needs to determine at what level domains are best served by cataloging standards. Are there commonalities in domains across languages and cultures? How should domain information be incorporated into cataloging standards? Focusing on domains could be an important step in meeting users' needs in a global environment, but more research is needed on how best to incorporate domain knowledge in cataloging standards.

\section{Conclusion}

In this paper, I address two questions: 1 . If cataloging standards are being used by diverse groups of users on a global scale, is the user-centered paradigm, as outlined by Dervin and Nilan (1986), still applicable? 2. If catalogers in practice cannot customize bibliographic records to meet users' needs, who/what is responsible for meeting users' needs and how should those needs be met? I suggest that focusing on users is still important, but the idea of what it means to be user-centered needs to change. Instead of placing the responsibility of meeting users' needs on cataloging practice, cataloging should actually focus on users in research and standards development. In addition, users should be studied as parts of domains, and standards should be based on an understanding of domains and their needs.

These ideas are not necessarily new, and perhaps there are better ideas out there, but the important thing is that cataloging needs to start a conversation on how best to meet users' needs. A little honesty and reflection is needed. Focusing on users is not easy, especially for broad representational systems, like library cataloging, that must meet the needs of many types of users. However, saying that the "convenience of the user" is the highest principle in the construction of cataloging codes, and instructing catalogers to keep users "in mind" while cataloging is not the same as actually meeting users' needs. The responsibility of meeting users' needs can no longer be placed on cataloging practice alone. Standards need to reflect the needs of many different users. If catalogers want to meet the needs of an increasingly global user base, they must find better ways to focus on users in order to have a true user-centered paradigm in cataloging and knowledge organization.

\section{References}

Allen, Thomas. J. 1969. Information needs and uses. Annual review of information science and technology 4: 1-29.

Anglo-American cataloguing rules. 2nd ed., rev. 2002. Chicago: American Library Association.

Bates, Marcia J. 1989. The design of browsing and berrypicking: Techniques for the online search interface. Online review 13: 407-423.

Bates, Marcia J. 1998. Indexing and access for digital libraries and the internet: Human, database, and domain factors. Journal of the American Society for Information Science 49: 1185-1205.

Belkin, Nicholas J. 1980. Anomalous states of knowledge as a basis for information retrieval. The Canadian journal of information science 5: 133-143. 
Berman, Sanford. 1971. Prejudices and antipathies: A tract on the LC subject heads concerning people. Jefferson, NC: McFarland \& Co.

Berman, Sanford. 1981. The joy of cataloging: Essays, letters, and other explosions. Phoenix: Oryx Press.

Borgman, Christine L. 1986. Why are online catalogs hard to use? Lessons learned from information-retrieval studies. Journal of the American Society for Information Science 37: $387-400$.

Borgman, Christine L. 1996. Why are online catalogs still hard to use? Journal of the American Society for Information Science 47: 493-503.

Carlyle, Allyson. 1999. User categorization of works: Toward improved organization of online catalogue displays. Journal of documentation 55: 184-208.

Cutter, Charles A. 1904. Rules for a dictionary catalog. 4th ed. Washington: Government Printing Office.

Dervin, Brenda and Nilan, Michael. 1986. Information needs and uses. Annual review of information science and technology 21: 3-33.

Dewey decimal classification. 22nd ed. 2003. Dublin, OH: OCLC.

Drabenstott, Karen, M., Simcox, Schelle, and Fenton, Eileen G. 1999. End-user understanding of subject headings in library catalogs. Library resources and technical services 43: 140-160.

Haykin, David Judson. 1951. Subject headings: A practical guide. Washington, D.C.: U.S. Government Printing Office.

Hjørland, Birger. 2002. Epistemology and the socio-cognitive perspective in information science. Journal of the American Society for Information Science and Technology 53: 257-270.

Hjørland, Birger and Albrechtsen, Hanne. 1995. Toward a new horizon in information science: Domain-analysis. Journal of the American Society for Information Science 46: 400-425.

Hoffman, Gretchen L. 2008. Negotiating normative institutional pressures and maintaining legitimacy in a complex work environment: A multiple case study of three academic cataloging units. Doctoral dissertation, Emporia State University.

Hufford, Jon R. 1991. The pragmatic basis of cataloging codes: Has the user been ignored? Major catalog codes published in the United States and Great Britain since 1841. Cataloging \& classification quarterly 14: 27-38.

Ingwersen, Peter. 1996. Cognitive perspectives of information retrieval interaction: Elements of a cognitive IR theory. Journal of documentation 52: 3-50.

Jeng, Ling Hwey. 1997. Knowledge, technology, and research in cataloging. Cataloging \& classification quarterly 24: 113-127.

Library of Congress classification: Classes A-Z. Washington, D.C.: Cataloging Distribution Service, Library of Congress.

Library of Congress subject headings. Washington, D.C.: Office for Subject Cataloging Policy, Library of Congress.

Mai, Jens-Erik. 2003. The future of general classification. Cataloging and classification quarterly 37 (1/2): 3-12.

Mai, Jens-Erik. 2004. Analysis in indexing: Document and domain-centered approaches. Information processing and management 41: 599-611.

McCombs, Gillian M. 1985. The reference librarian as middleman: Conflicts between catalogers and reference librarians. In Katz, Bill and Fraley, Ruth A. eds., Conflicts in reference services. New York: Haworth Press, pp. 17-28.

Montanelli, Dale. S. and Stenstrom, Patricia F. eds. 1999. People come first: User-centered academic library service. Chicago: Association of College and Research Libraries.

Olson, Hope A. 2000. Difference, culture and change: The untapped potential of LCSH. Cataloging \& classification quarterly 29: 53-71.

Olson, Hope A. 2001. The power to name: Representation in library catalogs. Signs: Journal of women in culture and society 26: 639-668. 
Olson, Hope A. 2004. The ubiquitous hierarchy: An army to overcome the threat of a mob. Library trends 52: 604-616.

Olson, Hope A. and Schlegl, Rose. 2001. Standardization, objectivity, and user focus: A metaanalysis of subject access critiques. Cataloging \& classification quarterly 32: 61-80.

Paisley, William. 1968. Information needs and uses. Annual review of information science and technology $3: 1-30$.

Statement of international cataloguing principles. 2009. Available: http://www.ifla.org/files/cataloguing/icp/ICP-2009 en.pdf

Stenstrom, Patricia F. 1999. Cataloging: A case study of self-imposed obsolescence. In Montanelli, Dale S. and Stenstrom, Patricia F. eds., People come first: User-centered academic library service. Chicago: Association of College and Research Libraries, pp. 65-78.

Weinberg, Bella Hass. 1992. A theory of relativity for catalogers. In Weinberg, Bella Hass ed., Cataloging heresy: Challenging the standard bibliographic product. Medford, N.J.: Learned Information, pp. 7-11. 